\title{
Prediction of recrystallisation in single crystal nickel-based superalloys during investment casting
}

\author{
Chinnapat Panwisawas ${ }^{1, \text { a }}$, Harshal N. Mathur ${ }^{2,3}$, Robert W. Broomfield ${ }^{1}$, Duncan Putman ${ }^{4}$ Catherine M.F. Rae ${ }^{2}$, \\ and Roger C. Reed ${ }^{5}$ \\ ${ }^{1}$ Department of Metallurgy and Materials, University of Birmingham, Birmingham B15 2TT, UK \\ 2 Department of Materials Science and Metallurgy, University of Cambridge, Cambridge CB3 OFS, UK \\ ${ }^{3}$ Institute für Metallkunde und Metallphysik, RWTH Aachen University, 52056 Aachen, Germany \\ ${ }^{4}$ Rolls-Royce plc., PO Box 31, Derby DE24 8BJ, UK \\ ${ }^{5}$ Department of Engineering Science, University of Oxford, Parks Road, Oxford OX1 3PJ, UK
}

\begin{abstract}
Production of gas turbines for jet propulsion and power generation requires the manufacture of turbine blades from single crystal nickel-based superalloys, most typically using investment casting. During the necessary subsequent solution heat treatment, the formation of recrystallised grains can occur. The introduction of grain boundaries into a single crystal component is potentially detrimental to performance, and therefore manufacturing processes and/or component geometries should be designed to prevent their occurrence. If the boundaries have very low strength, they can degrade the creep and fatigue properties. The root cause for recrystallisation is microscale plasticity caused by differential thermal contraction of metal, mould and core; when the plastic deformation is sufficiently large, recrystallisation takes place. In this work, numerical and thermo-mechanical modelling is carried out, with the aim of establishing computational methods by which recrystallisation during the heat treatment of single crystal nickel-based superalloys can be predicted and prevented prior to their occurrence. Elasto-plastic law is used to predict the plastic strain necessary for recrystallisation. The modelling result shows that recrystallisation is most likely to occur following $1.5-2.5 \%$ plastic strain applied at temperatures between $1000^{\circ} \mathrm{C}$ and $1300^{\circ} \mathrm{C}$; this is validated with tensile tests at these elevated temperatures. This emphasises that high temperature deformation is more damaging than low temperature deformation.
\end{abstract}

\section{Introduction}

In turbine blade applications for the jet engine, high performance materials are needed owing to the requirement for operation at elevated temperatures [1,2]. Suitable materials must display the following: (i) an ability to operate close to their melting point, (ii) resistance to chemical degradation and (iii) microstructural stability under static and cyclic loading conditions [3,4]. The nickel-based superalloys have emerged as the materials of choice for these applications. In practice, the geometry of a typical turbine blade is complex, involving many features and cooling passages and this necessitates the use of casting processes to manufacture them [5]. The casting of turbine blades - particularly in single crystal form is challenging, and quality control must be exercised to ensure that dimensional tolerances are met and defects are not present. Where this is not the case, castings must be scrapped causing considerable waste of time and money.

In practice, recrystallisation is a notable cause of scrap [4]. The root cause is the differential thermal contraction of the superalloy, mould and core during

\footnotetext{
${ }^{a}$ Corresponding author: c . panwisawas@bham . ac .uk
}

processing [6]. The alloy has a tendency, at any given temperature, to have a coefficient of thermal expansion greater than that of the mould and core. This leads to concentration of stress around the ceramic core and mould; moreover, its magnitude can be so great that localised plastic yielding can occur in the alloy [6,7]. When this is the case, the driving force can be large enough for recrystallised grains to form during subsequent heat treatment $[8,9]$. Therefore, it is worth studying the phenomenon of recrystallisation in single crystal superalloys in detail in order to determine how sensitive these are to the accumulated levels of plastic strain and the heat treatment conditions. Studies of the recrystallisation phenomenon in the literature are rather rare to this point, despite its technological importance.

The detailed questions to be addressed are as follows. At what temperature during cooling is the plastic deformation introduced? And at what strain levels? [10] Ideally, the material response to the plastic strain in high temperature range should be studied and rationalised to provide guidance for the turbine blade designers to avoid recrystallisation in specific geometries. Moreover, the sensitivity to the geometrical variations, processing 
parameters and materials properties should be researched in a rigorous manner.

\section{Method}

\subsection{Modelling approach}

To represent an analogue of a turbine blade aerofoil, a simplified "bobbin" geometry was designed as described in [6] and shown in Fig. 1. The mechanical constraints provided by platforms and shrouds have been simulated during the process of investment casting. With the various geometries of bobbins the stress concentration features and ceramic core geometries were taken into account. Finite element method was carried out using commercially available ProCAST software. Elasto-plastic law assuming rate independence with high-temperature plasticity was used. Material parameters for the CMSX-4 ${ }^{\mathrm{C}}$ single crystal superalloy ${ }^{1}$ were assumed to be temperature dependent. Detailed calculation can be found in [6].

\subsection{Experimental}

\subsubsection{Casting trials}

Some bobbin geometries identified in Table 1 of [6] have been fabricated from CMSX-4 single crystal superalloy. A single-shot investment casting facility at University of Birmingham was employed. Moulds were prepared using wax assembly, ceramic processing and steam-autoclave dewaxing methods, following standard procedures. During the casting a withdrawal rate of $0.06 \mathrm{~mm} \mathrm{~s}^{-1}$ was used; and the subsequent solution heat treatment was done at a peak temperature of $1315^{\circ} \mathrm{C}$ for $6 \mathrm{hr}$ [7].

Longitudinal EDM wire cut was used and followed with mounting, polishing in the usual metallurgical approach. Etching was done either with a $\mathrm{HCl} / \mathrm{H}_{2} \mathrm{O}_{2}$ solution, or Kallings' reagent composed of $10 \mathrm{~g}$ Cupric Chloride, $50 \mathrm{ml}$ Hydrochloric Acid and $50 \mathrm{ml}$ Ethanol. The electron backscattered diffraction (EBSD) detector was employed to observe the local misorientation map (kernel method, $11 \times 11$ pixel matrix) at the as-cast surface. The sample was positioned at $70^{\circ}$ angle to the EDSB detector, and data was acquired at $25 \mathrm{kV}$ with $30 \mathrm{~mm}$ working distance.

\subsubsection{Tension-compression testing}

Deformation testing in compression and tension of ascast CMSX-4 was carried out at different temperatures in order to evaluate the critical straining conditions necessary for recrystallisation. Compression samples were sliced from as-cast bars, such that their external convex surfaces were consistent with an as-cast surface finish; they were of $10 \mathrm{~mm}$ diameter and $12 \mathrm{~mm}$ length. Moreover, tensile straining samples were machined to $3 \mathrm{~mm}$ gauge diameter and $15 \mathrm{~mm}$ gauge length by low-stress grinding. At temperature these were strained uniaxially parallel to $\langle 001\rangle$ at $0.2 \% \mathrm{~min}^{-1}$ under compression and tension. The strained samples were subsequently subjected to the

\footnotetext{
${ }^{1}$ CMSX-4 is a registered trademark of Cannon Muskegon Corporation.
}

standard solution heat treatment for CMSX-4. All samples were sectioned longitudinally along $\langle 001\rangle$ for examination.

\subsubsection{As-cast tensile testing}

As-cast tensile testpieces of diameter $5.85 \mathrm{~mm}$ and gauge length $29 \mathrm{~mm}$ were prepared and cast in a single shot furnace at University of Birmingham. Considerable care was taken to ensure that the surface finish was good enough in terms of acceptable surface roughness to be representative of the casting process. The standard CMSX4 material was used for this purpose. The orientation of all samples was controlled to be within $20^{\circ}$ of the $\langle 001\rangle$ solidification direction. Deformation testing in tension of as-cast samples was carried out at different temperatures in order to evaluate the critical straining conditions necessary for recrystallisation. Special care was taken to machine the both ends of testpieces to allow the testpieces to fit the tensile machine. Gauge length section was kept the same as it was after casting. At temperature these were pulled uniaxially in tension parallel to $\langle 001\rangle$ at $0.2 \% \mathrm{~min}^{-1}$. The strained samples were subsequently subjected to the standard solution heat treatment for CMSX-4. All samples were sectioned longitudinally along $\langle 001\rangle$ with EDM for examination. The electrolytic etching process of a $\mathrm{HCl} / \mathrm{H}_{2} \mathrm{O}_{2}$ etch was used to reveal the sample surface.

\subsubsection{Transmission electron microscopy}

Transmission electron microscopy (TEM) was used to study the deformation induced during the investment casting process. As cast bars of the CMSX-4 superalloy, which was not subject to tensile straining, were used for this purpose. For sample preparation, discs of $\sim 3 \mathrm{~mm}$ diameter and $0.2-0.3 \mathrm{~mm}$ thickness were subjected to twin-jet electropolishing with $10 \%$ perchloric acid solution in methanol; $20.5 \mathrm{~V}$ and $-5^{\circ} \mathrm{C}$ were the working conditions. A JEOL 200CX TEM was used at an accelerating voltage of $200 \mathrm{kV}$ for bright field imaging of the deformed microstructure.

\section{Results}

Finite element calculation has been employed to investigate the effect of casting cross-section, stress concentration, its location and the presence of a core. Figure 1 has essentially provided the information of the critical plastic strain for recrystallisation, which is in the range of 1.42-2.34\%. As indicated from a hollow bobbin casting with $1.5 \mathrm{~mm}$ wall thickness, recrystallisation was found after solution heat treatment. Further information about modelling results can be found in [6]. One of the most interesting aspects is that the deformation mode within the aerofoil section was in tension. Some regions, e.g. platform and shroud, were in compression. The question is what effect of deformation mode does influence recrystallisation.

To test this argument, one would need to design a set of tension/compression tests in a wide range of temperatures and plastic strains, see Fig. 2. It was found that the critical plastic strain for recrystallisation in compression is lower than that in tension. Only $0.2 \%$ plastic strain in 


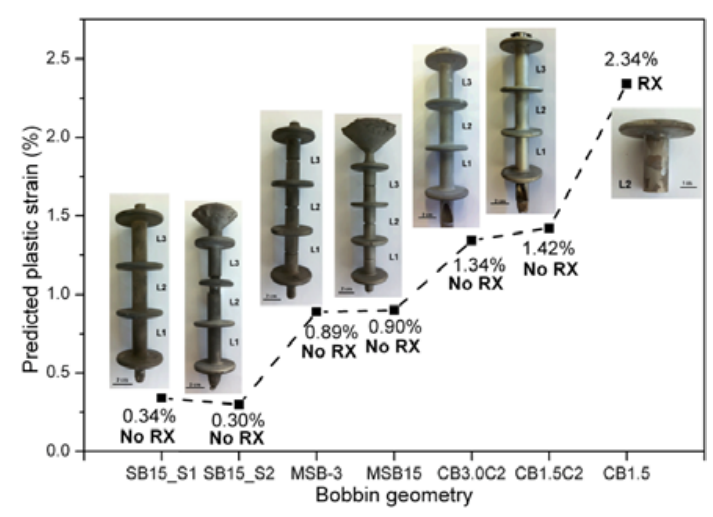

Figure 1. Variation of predicted plastic stain in the casting quoted in [2] and associated experimental observation of recrystallisation after solution heat treatment.
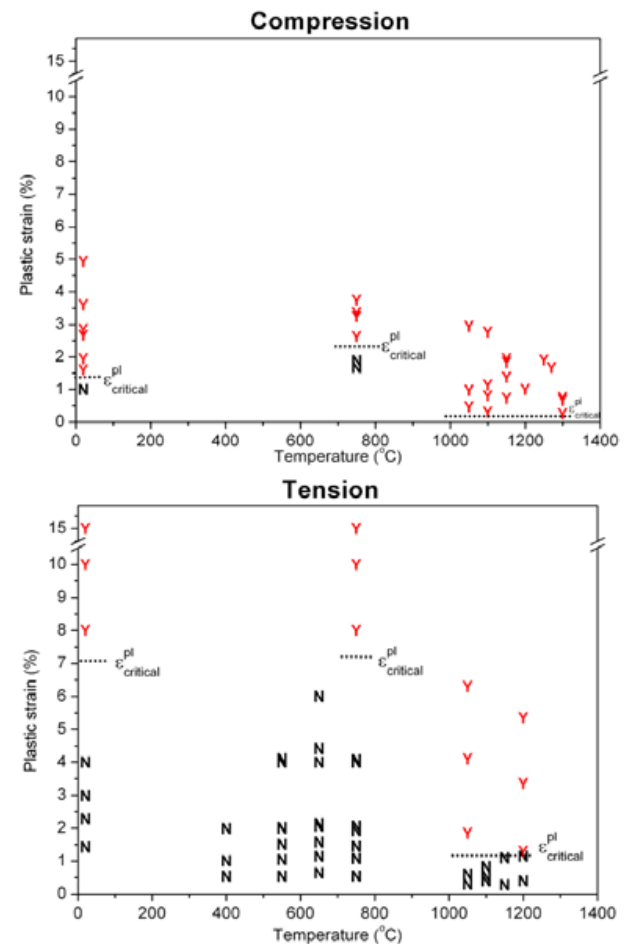

Figure 2. Tension/compression asymmetry test results.

compression can lead to recrystallisation at temperatures above $1000{ }^{\circ} \mathrm{C}$; whereas about $1.5 \%$ plastic strain is required to create recrystallised grains in tension.

It was found that full recrystallisation is observed to occur from the circumference of the cylindrical sample, see Fig. 3. If the number of recrystallised grains were plotted versus plastic strains, with higher strain the number of recrystallised grains is greater, as seen in Fig. 4.

One needs to emphasise that the as-cast surface of compression samples was grit-blasted; therefore the high local strain is introduced to the sample and it is one of possible reasons that recrystallisation was found from the surface of the samples. In addition, the surface of tensile samples was machined before testing. This is not a surface representative to that of the investment casting process.

However, the tension/compression tests suggested that high temperature deformation is more damaging than

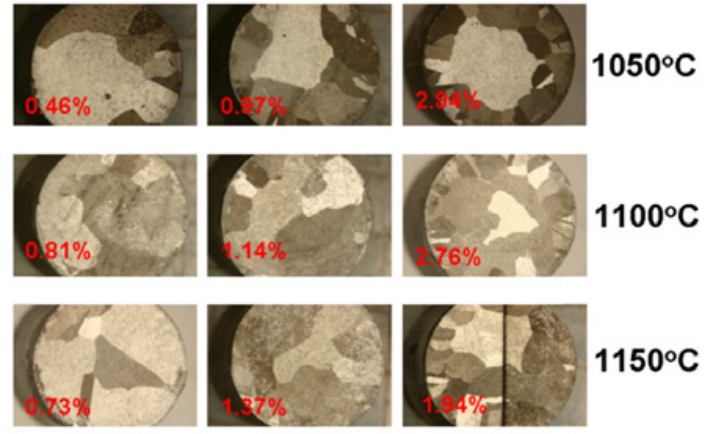

$\underline{5 \mathrm{~mm}}$

Figure 3. Recrystallisation found after compression test at different plastic strains and temperatures; all subjected to the standard solution heat treatment.

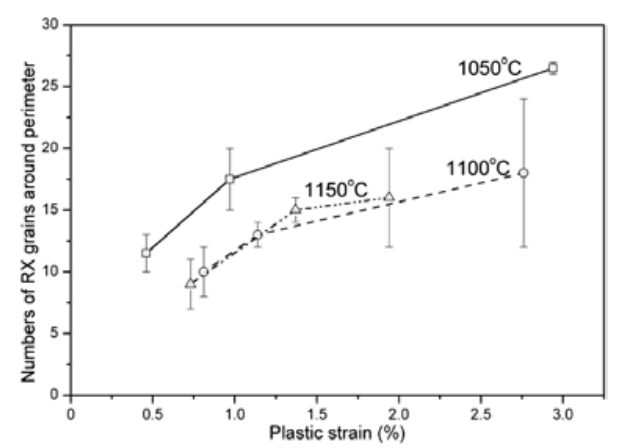

Figure 4. Variation of plastic strain and numbers of recrystallised grains around perimeter in compression samples.

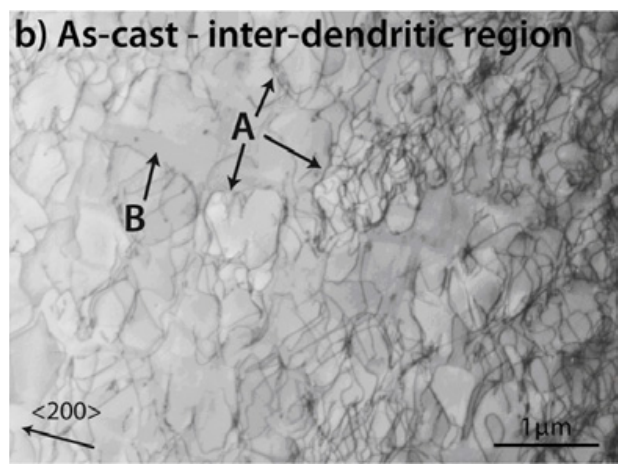

Figure 5. Dislocation structures of an as-cast sample in interdendritic region, not subject to tensile straining [2].

low temperature. Moreover, higher critical strain for recrystallization is expected in tension compared with compression, and surface condition plays an important role in recrystallisation [11]. Our previous work has shown that plastic deformation during investment casting is introduced at high temperatures [6], evidenced by the dislocation structure of an as-cast bar of CMSX-4, see Fig. 5.

On comparing with known conditions it was seen that straining above $1000{ }^{\circ} \mathrm{C}$ formed dislocation networks at the $\gamma / \gamma^{\prime}$ interface, as in Fig. 5, leaving the $\gamma$ channels relatively dislocation-free. The TEM observation supports the deduced temperature range over which casting deformation is induced at high temperatures. This is consistent with results from the process modelling of the 

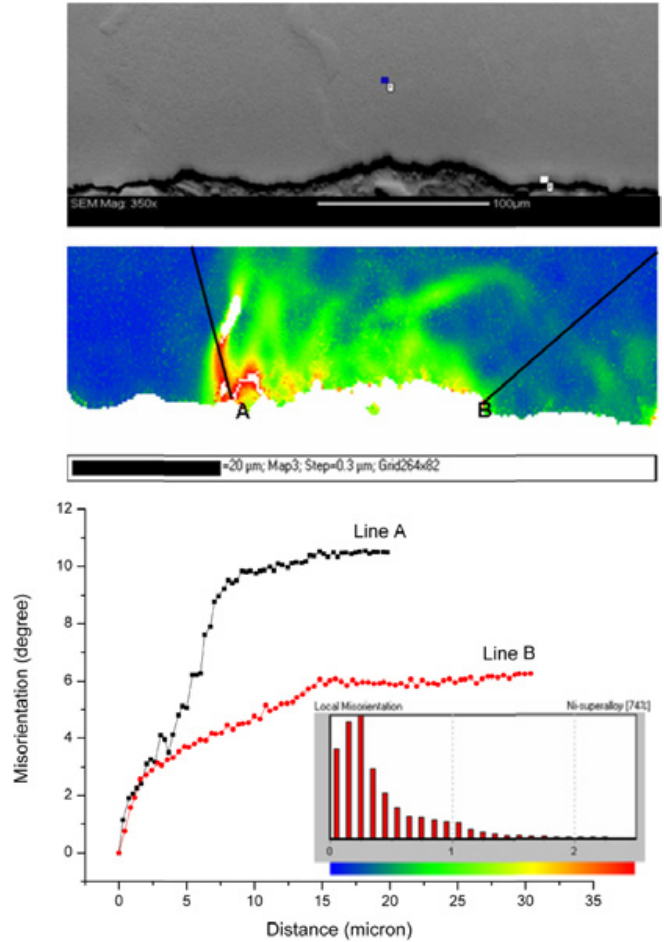

Figure 6. Local misorientation map near the as-cast surface of a hollow bobbin testpiece, leading to recrystallisation after SHT.

bobbin testpieces, where casting deformation was induced at high temperatures [6].

Apart from the role of high temperature deformation to recrystallisation, the surface condition is rather important. It has been observed that in an as-cast hollow bobbin testpiece, which is predicted to have $2.34 \%$ plastic strain in the gauge regions (see Fig. 1), can show localised misorientations of up to 10 degree at the cast surface, as shown in the plot of misorientation versus distance from the bulk of the sample to the as-cast surface, lines $\mathrm{A}$ and $\mathrm{B}$ in Fig. 6, indicating the presence of high local surface strain from the casting process. Therefore, it can be concluded that high temperature deformation in tension with the representative as-cast surface is the most complete figure to be used for constructing critical strain data for recrystallisation in a single crystal superalloy.

With all above in mind, as-cast tensile samples were designed to (i) create data of critical plastic strain required for recrystallisation in a single crystal superalloy, and (ii) provide yield stress data for an as-cast material to be employed as predictive capability can be consequentially improved.

Figure 7a illustrates that recrystallised grains initiated from the as-cast surface for all recrystallised testpieces at the range of plastic strains and temperatures shown in Fig. 7b. It has been found that critical plastic strain for recrystallisation is in the range of $1.5-2.0 \%$ at the temperatures above $1000^{\circ} \mathrm{C}$, and this is consistent with the predicted plastic strain for recrystallisation from the finite element calculations that are validated in Fig. 1.

Most importantly, it has been found that the yield stress of the as-cast CMSX-4 at temperatures below $1000^{\circ} \mathrm{C}$ has not changed significantly (Fig. 8a), while the temperatures (a)

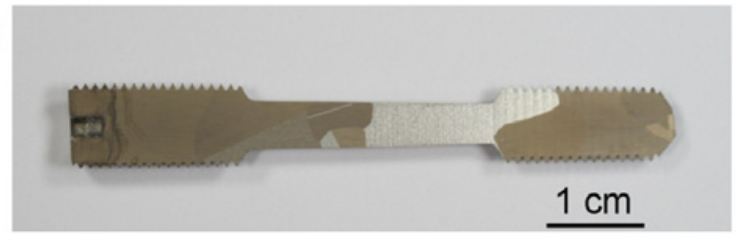

(b)

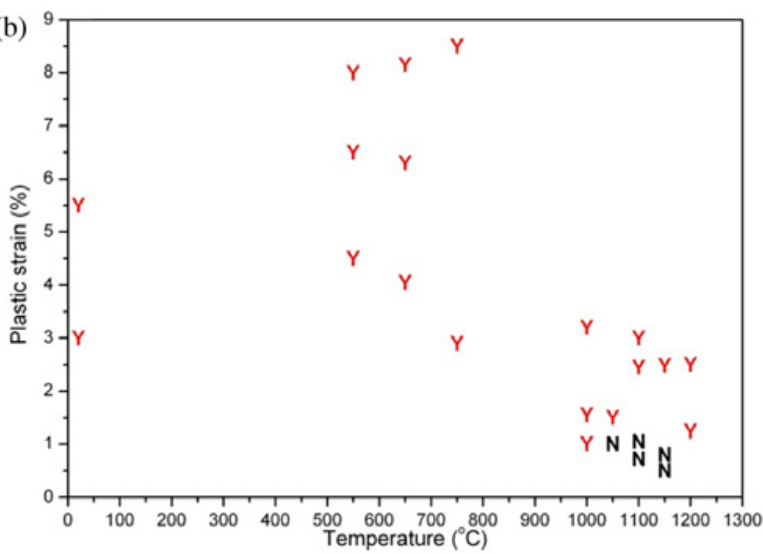

Figure 7. As-cast tensile test: (a) a sample of tensile plastic strain of $2.53 \%$ at $1050{ }^{\circ} \mathrm{C}$ post-solutioning, (b) critical strain data for recrystallisation: " $\mathrm{N}$ " means no recrystallisation and " $\mathrm{Y}$ " means recrystallisation occurred.

above $1000^{\circ} \mathrm{C}$ have indicated some rate-dependent plastic deformation, evidenced by decreasing in apparent Young's moduli with increase in temperature (Fig. 8b).

\section{Discussions}

As a final check of the conclusions drawn from this work, as-cast bars of CMSX-4 were cast and uniaxially strained, at temperatures between $20^{\circ} \mathrm{C}$ and $1200^{\circ} \mathrm{C}$. They were then subjected to the standard solutioning heat treatment to determine whether recrystallisation did indeed occur. Note that the testpieces were prepared with gauge length in the as-cast condition; consistent with the sense of stress expected in practice, testing was carried out in tension. Figure $7 \mathrm{~b}$ summarises the conditions of temperature and induced plastic strain which were found to induce recrystallisation. The results indicate that the critical plastic strain needed to induce recrystallisation in CMSX-4 is in the range 1.5-2.0\%, when it is introduced at temperatures of $1000{ }^{\circ} \mathrm{C}$ or higher. The TEM observations in Fig. 5 confirm that this is the critical temperature range as deformation during investment casting occurs at high temperatures only. Figure $8 \mathrm{~b}$ shows that at such temperatures low stresses are sufficient to induce plasticity in the superalloy; moreover, in practice, at temperatures lower than $750^{\circ} \mathrm{C}$ the higher cooling stresses (Fig. 8b) exceed the fracture strength of the ceramic mould, causing no deformation of the superalloy at low temperatures.

Compared to Fig. 2b the critical plastic strains below $700{ }^{\circ} \mathrm{C}$ have reduced significantly due to the change in the surface condition. However, the results indicate that intrinsically, i.e. without the as-cast surface, low temperature deformation is less damaging for recrystallisation. This is perhaps because the low temperature dislocation microstructure, which is characterised by dislocations 

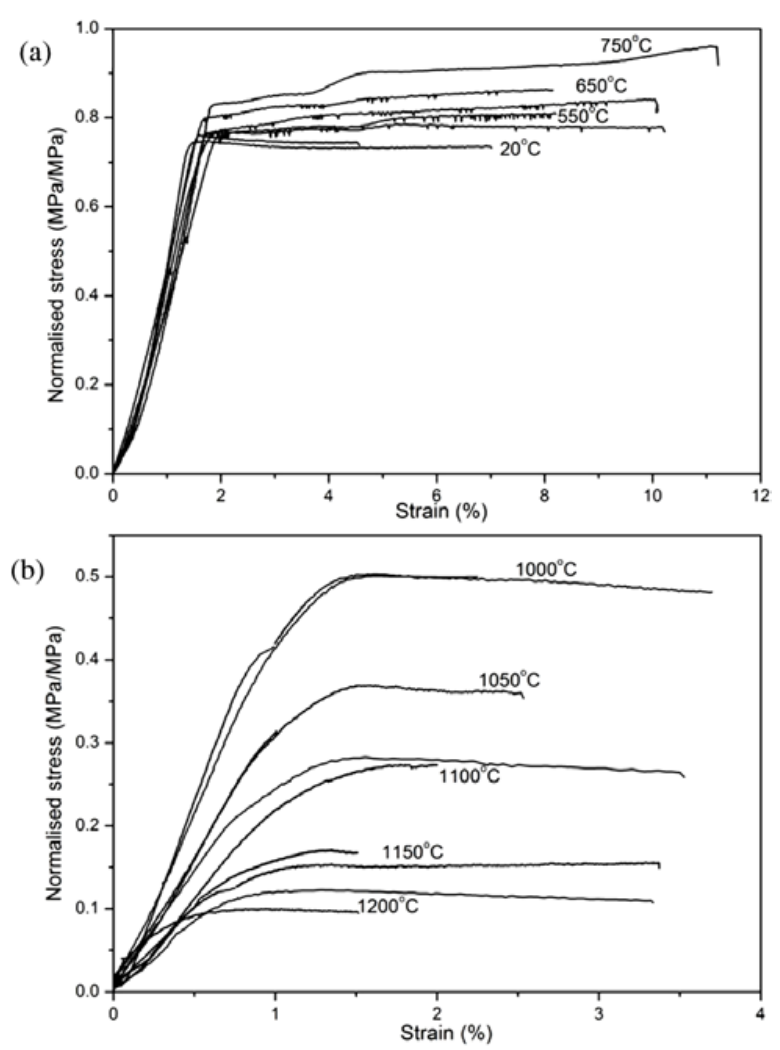

Figure 8. Stress-strain curves from the as-cast tensile test at temperatures: (a) below $1000^{\circ} \mathrm{C}$ and (b) above $1000^{\circ} \mathrm{C}$.

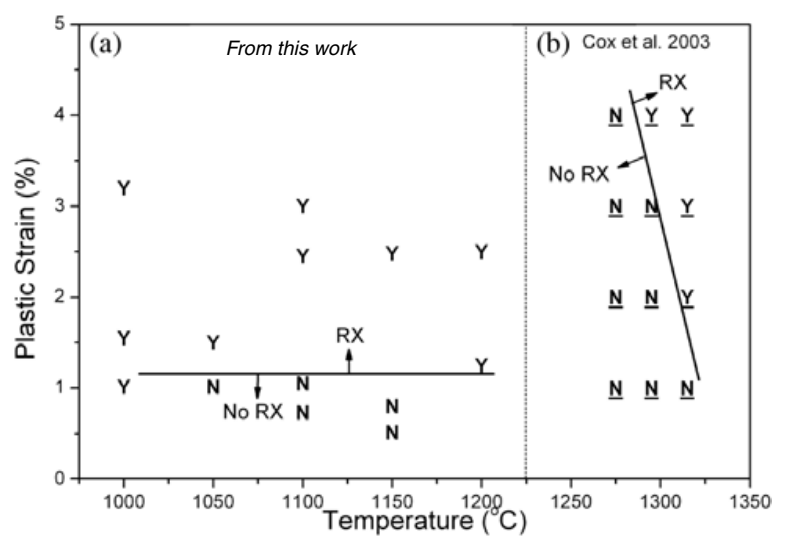

Figure 9. Strain data for recrystallisation in (a) as-cast tensile testpieces from this work and (b) Cox et al. 2003: "N" means no recrystallisation and " $\mathrm{Y}$ " means recrystallisation occurred.

shearing the $\gamma$ and $\gamma^{\prime}$ phases (cf. Fig. 21 of Ref. [6]), recovers more than the high temperature equivalent during annealing. This offers greater tolerance, for example, for post-casting processes in the foundry.

Figure 9 shows critical strain data for recrystallisation from this work and from Cox et al. [7]. It can be seen that a higher plastic strain and annealing temperature is necessary to promote recrystallisation in the work of Cox et al. [7], when comparing to the present results. There are two reasons for this. First, the conditions of the superalloy were different. Even though Cox et al. used as-cast materials for the tensile strain experiment, the surface conditions were different. In this work, the surface, which is believed to be the source of nucleation sites for recrystallisation, was maintained in the as-cast state. In the work of Cox et al. [7], machined test pieces were used. This means sources of recrystallisation were removed in machined samples. Second, the machined test pieces in [7] were strained in tension along $\langle 001\rangle$ to a fixed amount of strain at room temperature and then subjected to 6-hour homogenization heat treatment, see Fig. 6. As discussed above, low temperature deformation is less damaging than high temperature one, given that as-cast surface is removed. In order to cause recrystallisation during heat treatment one needs sufficient plastic deformation. The fact that dislocation activity is limited to the $\gamma$ phase at high temperatures means that a lower plastic strain leads to sufficient localised plastic strain to cause recrystallisation.

The assumption of elasto-plastic law for the modelling can be improved by considering and defining more precise flow stress data of the material at high temperatures (above $\left.1000^{\circ} \mathrm{C}\right)$. Moreover, the rate-dependent creep plasticity has played its role at temperatures above $1000^{\circ} \mathrm{C}$, indicated in Fig. 8b. The effect of creep deformation on recrystallisation should be observed further. In addition to this, material models of ceramic mould and shell would be rather important for correctly predicting process-induced plastic strains in the metal and this is also a way to increase predictive capability of recrystallisation in single crystal superalloys.

To prevent recrystallisation during investment casting, one needs to consider the component geometry also, as illustrated in Fig. 1 since different designs can lead to levels of process-induced plastic strains. If one uses the model to predict the level of strain, recrystallisation can subsequently be mitigated. Another possible approach to avoid or even suppress recrystallisation is to get rid of the source of nucleation for recrystallisation [11]. By removing the as-cast surface, one can expect less recrystallisation.

\section{Conclusions}

Recrystallisation in a single crystal superalloy during investment casting has been presented in this paper. Some specific conclusions are:

- Recrystallisation was found in a hollow bobbin casting with $1.5 \mathrm{~mm}$ wall thickness after solution heat treatment. The model predicted that $2.34 \%$ plastic strain was induced in the testpieces.

- Surface condition can play an important role to recrystallisation.

- Local misorientation up to 10 degrees was observed under EBSD on the as-cast surface of a hollow bobbin casting with $1.5 \mathrm{~mm}$ wall thickness. This led to recrystallisation after solutioning.

- As-cast tensile test is then designed to produce critical strain data for recrystallisation of a single crystal superalloy during investment casting. It was found that $1.5-2.0 \%$ of tensile plastic strain induced at high temperatures can give rise to recrystallisation after heat treatment. Moreover, 
the tensile test result suggested further that ratedependent plasticity can have a pertinent effect on recrystallisation, which is needed to be taken into account to improve the predictive capability.

Two of the authors, Chinnapat Panwisawas and Harshal N. Mathur, acknowledge support from the Engineering \& Physical Sciences Research Council (EPSRC) and Rolls-Royce plc, in the form of Dorothy Hodgkin Postgraduate Awards (DHPAs). Helpful discussions with Paul Brown and Neil Jones of RollsRoyce plc are acknowledged. The provision of the ProCAST software by the ESI Group - and the help of Dr Rajab Said in organising - is acknowledged as part of the PRISM ${ }^{2}$ collaboration at the University of Birmingham.

\section{References}

[1] R.W. Cahn, Nature, 309 (1984)

[2] C.T. Chou, P.B. Hirsch, M. McLean and E. Hondros, Nature, 300 (1982)
[3] W. Betteridge and S.W.K. Shaw, Mater. Sci. Tech., 3 (1987)

[4] R.C. Reed, The superalloys: fundamentals and applications (Cambridge University Press, Cambridge, 2006)

[5] G.A. Whittaker, Mater. Sci. Tech., 2 (1986)

[6] C. Panwisawas, H. Mathur, J.-C. Gebelin, C.M.F. Rae and R.C. Reed, Acta Mater. 61, 1 (2013)

[7] D.C. Cox, B. Roebuck, C.M.F. Rae and R.C. Reed, Mater. Sci. Tech., 19 (2003)

[8] L. Wang, F. Pyczak, J. Zhang and R.F. Singer, J. Mater. Sci. 100, 8 (2009)

[9] L. Wang, F. Pyczak, J. Zhang, L.H. Lou and R.F. Singer, Mater. Sci. Eng. A, 532 (2012)

[10] C. Panwisawas, J.-C. Gebelin and R.C. Reed, Mater. Sci. Tech. 29, 7 (2013)

[11] H. Mathur, C. Panwisawas, C.N. Jones, R.C. Reed and C.M.F. Rae, Acta Mater. (Submitted) 